
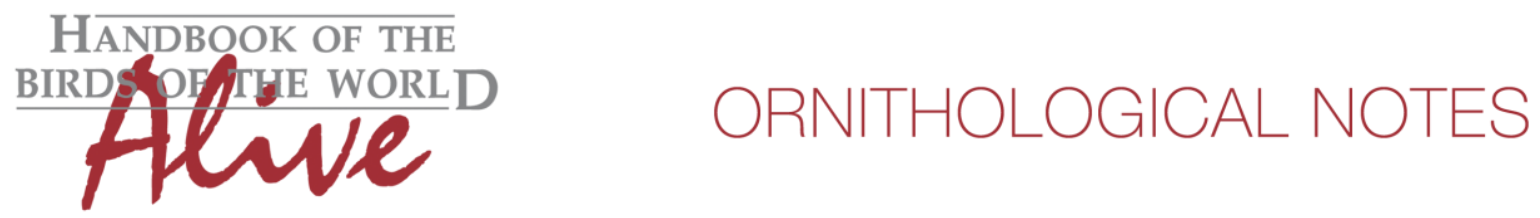

\title{
Notes on the vocalizations of Rock Martin (Ptyonoprogne fuligula)
}

Peter Boesman

In the following we briefly analyze and compare voice of the different races of Rock Martin (Ptyonoprogne fuligula). We also try to quantify the extent of any vocal differences using the criteria proposed by Tobias et al. (2010), as a support for taxonomic review.

We have made use of sound recordings available on-line from Xeno Canto (XC), Macaulay Library (ML) and recordings from Southern Africa by Guy Gibbon.

There are very few recordings available. An overview:

obsoleta group (N)

flight call
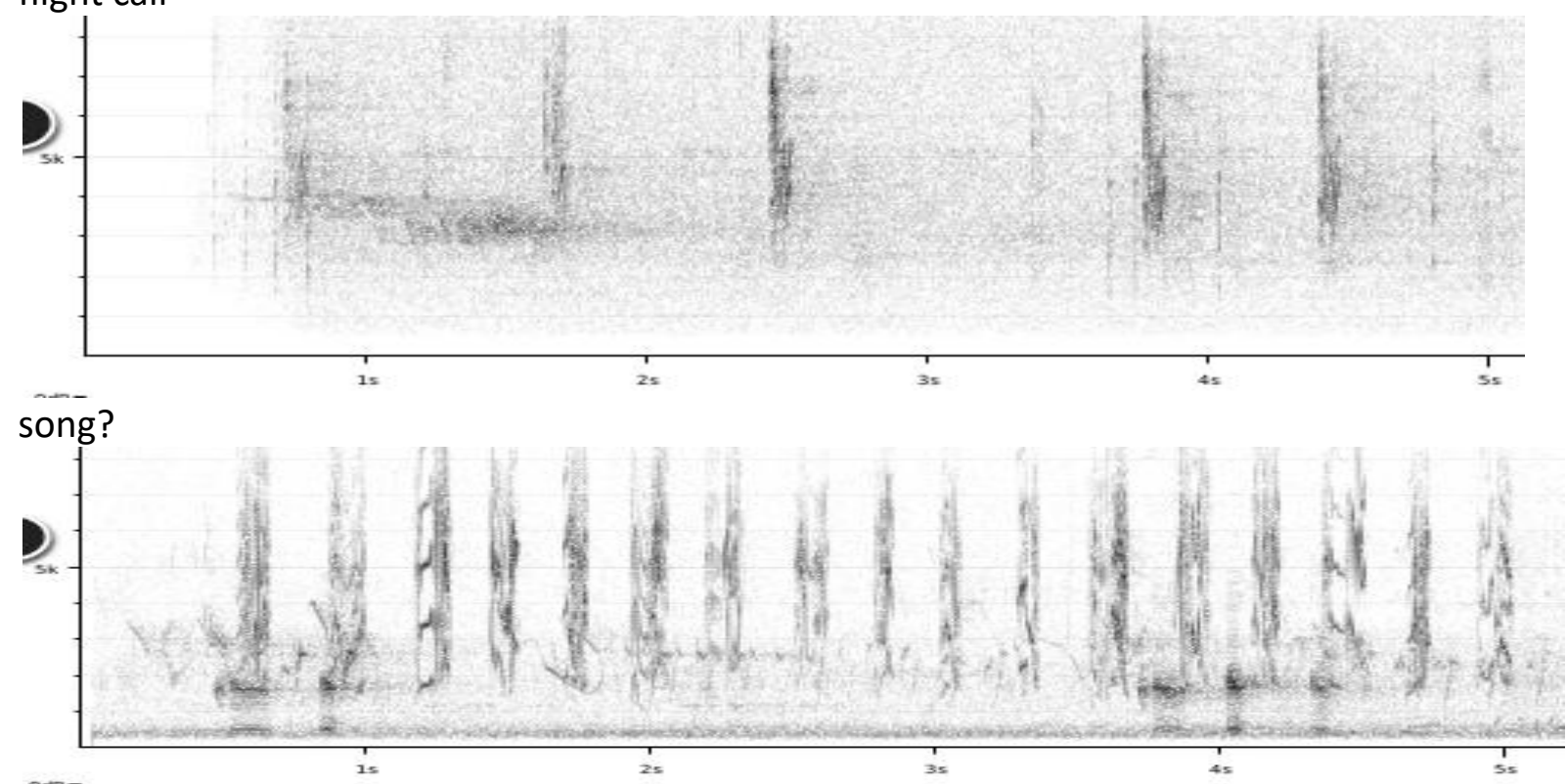

fusciventris group (W, C, E)

flight call

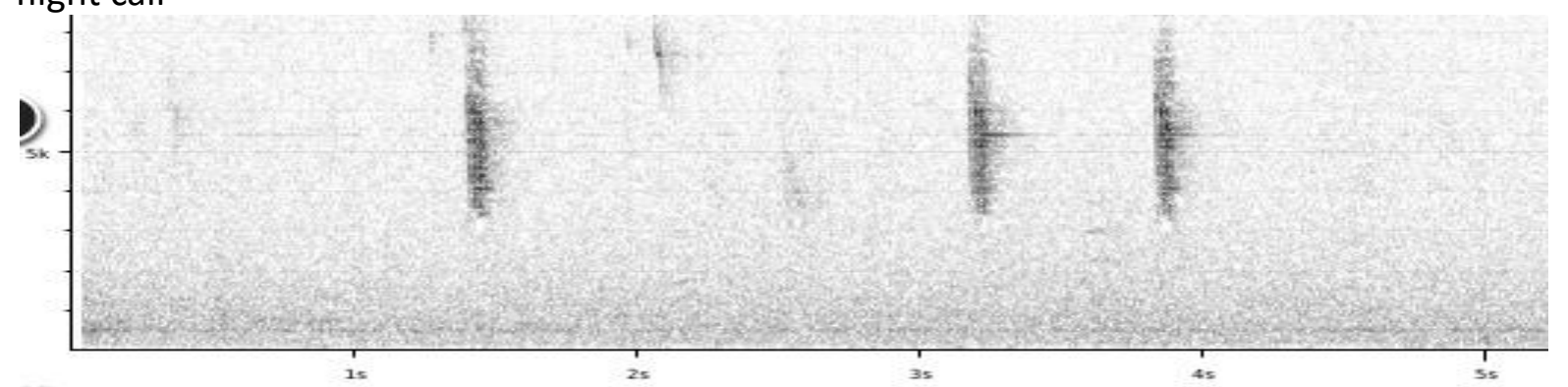




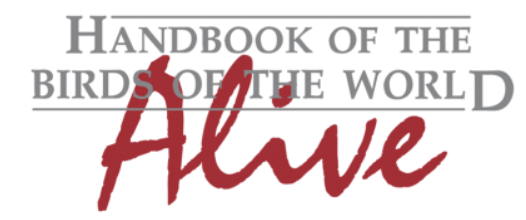

\section{ORNITHOLOGICAL NOTES}

nominate group (S)

flight call

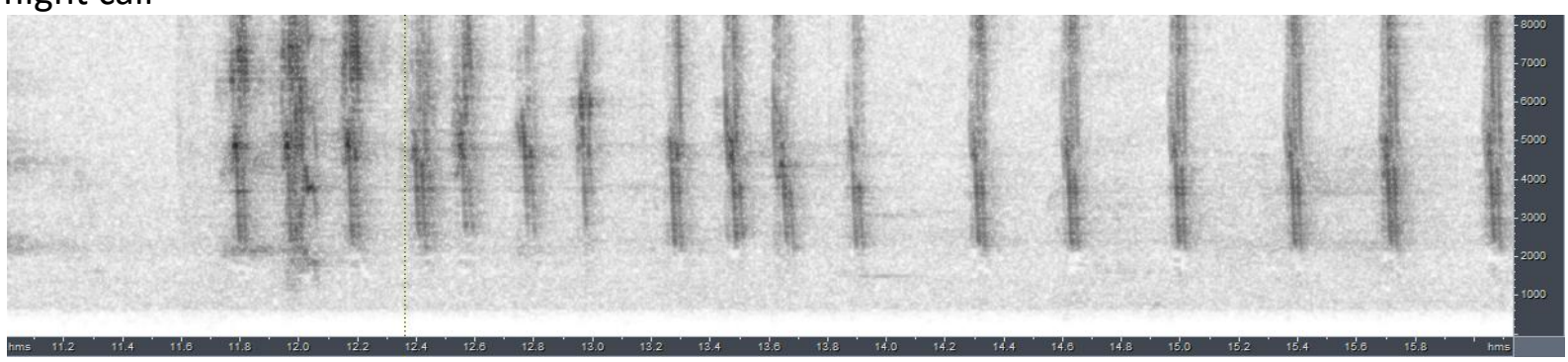

song?

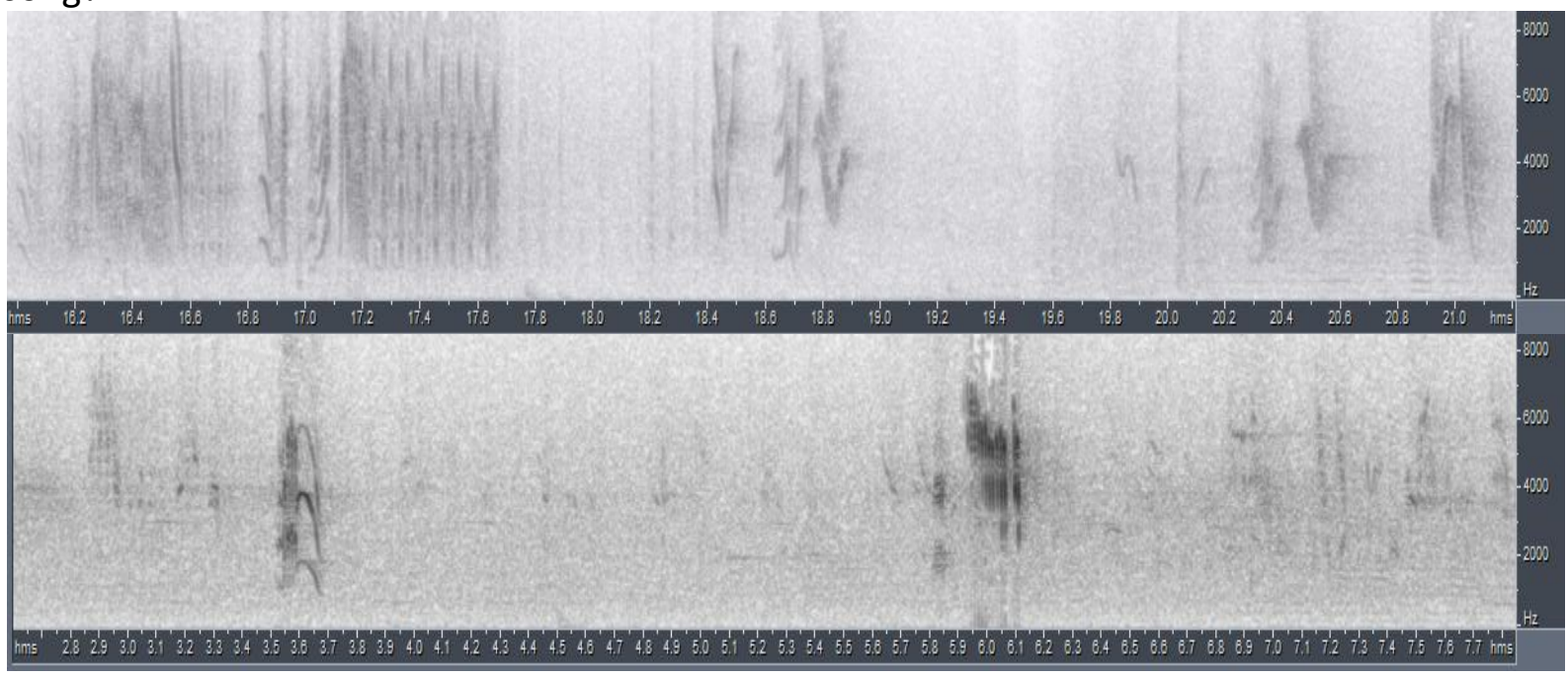

Based on these very few recordings, it would seem that flight call of nominate group is much lower pitched, sounding like sparrow chips rather than the more buzzy chirps from other races (main energy between $2-5 \mathrm{kHz}$ vs between $3-7 \mathrm{kHz}$ ). If confirmed by more recordings, this would lead to a vocal score of 2.

There are too few recordings to conclude anything about song differences.

At the other hand, flight call of obsoleta and fusciventris group don't seem to differ.

This note was finalized on 17th February 2016, using sound recordings available on-line at that moment. We would like to thank in particular the sound recordists: Thijs Fijen, Guy Gibbon, Linda Macaulay, Rory Nefdt and Herman Van Oosten.

\section{References}

Tobias, J.A., Seddon, N., Spottiswoode, C.N., Pilgrim, J.D., Fishpool, L.D.C. \& Collar, N.J. (2010). Quantitative criteria for species delimitation. Ibis 152(4): 724-746.

\section{Recommended citation}

Boesman, P. (2016). Notes on the vocalizations of Rock Martin (Ptyonoprogne fuligula). HBW Alive Ornithological Note 238. In: Handbook of the Birds of the World Alive. Lynx Edicions, Barcelona. (retrieved from http://www.hbw.com/node/932201 on 29 September 2016). 